ments, is consistent with an early mammalian radiation always retaining something of the ancestral sprawling gait. Two complete humeri from the Eocene have been published as stereophotographs and show features to support this ${ }^{8}$, including a marked residuum of the primitive torsion between humeral head and elbow condyle. Sereno and McKenna ${ }^{2}$ now argue from the features of their beautiful specimen of a small, Late Cretaceous multituberculate forelimb that it was very like that of therians and was swung parasagittally over a considerable range. A corollary is that therians and multituberculates share this advance, not shown by monotremes. Non-palaeontologists should note that the methods used in these studies are not speculative descriptions of how the dead bones may have articulated and moved: a considerable number of osteological features are scored objectively to evaluate functional and phylogenetic correlations. However, many fossil specimens show cracks and distortions which can make biometrics inexact.

There is need for caution in relation to these new conclusions. The detail is obtained from one or two species in a long-lived radiation that must have adapted to a variety of niches. How likely is it that all multituberculates over this huge time span were restricted to low-frequency hearing? If the forelimb was advanced in a Cretaceous form and primitive in an Eocene form, from the same taeniolabidoid group, how secure is any assumption about the timing of the advance? We derive from marsupials and placentals knowledge of a broad range of adaptions, but the monotremes, platypus and echidna, are very specialized in locomotion and hearing, and we still only guess at the primitive ancestral form. With important new material coming from the efforts of Australian palaeontologists and from the recent American-Mongolian expeditions, we can hope that more well preserved skeletal finds will provide both interesting answers and surprises within this somewhat neglected part of our family history.

Robert Presley is in the School of Medical and Molecular Biosciences, University of Wales, Box 911, Cardiff CF1 3UA, UK.

1. Meng, J. \& Wyss, A. R. Nature 377, 141-144 (1995).

2. Sereno, P. C. \& McKenna, M. C. Nature 377, 144-147

2. Sereno,

3. Gambaryan, P. P. \& Kielan-Jaworowska, Z. Acta palaeontol.

Polon. 40, 45-108 (1995).

4. Butler, P. M. \& Macintyre, G. T. Phil. Trans. R. Soc. B345, 433-458 (1994).

5. Clemens, W. A. \& Kielan-Jaworowska, Z. in Mesozoic Mammals (eds Lillegraven, J. A. Kielan-Jaworowska, Z. \& Clemens, W. A.) 99-149 (Univ. California Press, Berkeley, 1979)

6. Miao, D. \& Lillegraven, J. A. Natn. geogr. Res. 2, 500-507 (1986).

7. Kielan-Jaworowska, Z. \& Gambaryan, P. P. Fossils Strata 36, 1-92 (1994).

8. Kielan-Jaworowska, Z. \& Qi, T. Vertebrata PalAsiatica 28 81-94 (1990).

\title{
More genes versus environment
}

\section{Byron H. Waksman}

ON page 150 of this issue ${ }^{1}$, Ebers et al. describe the results of a painstaking study of 15,000 patients suffering from multiple sclerosis (MS). Their conclusion is that the aggregation of MS cases within families is determined entirely by genetic factors and is not influenced by shared environmental factors like infection. This vexing genes-versus-environment issue has been convincingly resolved as a result of the authors' comprehensive screening of adoptive first-degree 'relatives' of a large, fully ascertained and well studied population of MS patients from fourteen clinics across Canada.

In a sense, these findings are not surprising. It is now widely thought that MS is the result of an immunologically mediated, quite possibly autoimmune, process. Susceptibility to MS seems to be determined, in part, by the genes that encode elements of the trimolecular complex involved in recognition by $T$ cells. These include the major histocompatibility complex (MHC), certain T-cell receptor peptide sequence polymorphisms and encephalitogenic peptides of brain protein antigens; also implicated are genes governing elements of the immunologically determined inflammatory process. The high concordance of MS in monozygotic twin pairs and in first-degree relatives of individuals with MS, cited by Ebers $e t$ $a l .{ }^{1}$, is an expression of these genetic influences.

But although Ebers and co-workers were unable to detect any effect attributable to shared environment, things may not be quite so simple. These authors only addressed the question of MS prevalence among non-biological 'relatives' living with an MS case, most of whom do not carry genes for MS susceptibility. But shared environment undoubtedly does play a part in the induction of disease among biological relatives who live with

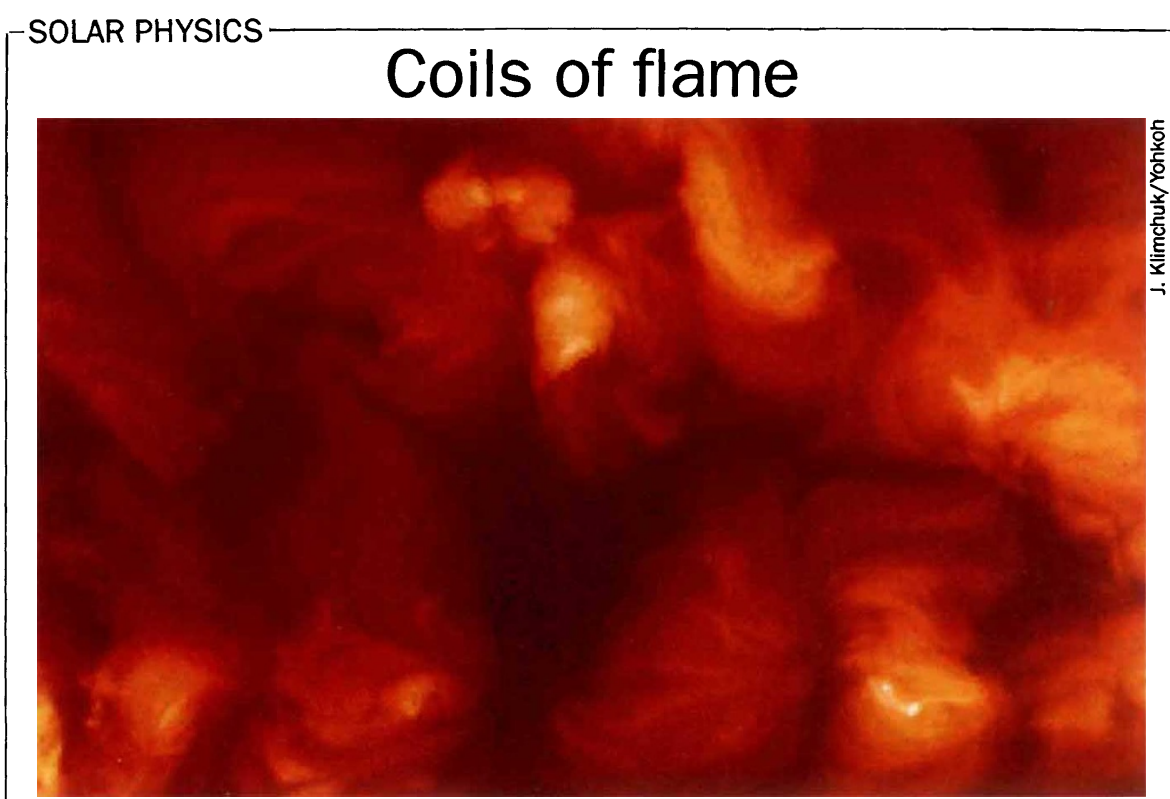

THESE fiery coils would have been the delight of any Renaissance painter, could he only have seen them. But the image shown here is not a snippet from the head of some Titian beauty. Instead, the arching, twisted loops are an X-ray telescope's view of the solar corona, where the gas - fiery indeed - is at a temperature of several million kelvin. How the gas is heated to this extent was the question exercising James Klimchuk and Lisa Porter, whose research is reported on page 131 of this issue and in a paper to appear in the Astrophysical Journal. From observations of long-lived coronal loops made with the soft X-ray telescope aboard the Japanese Yohkoh satellite (the name means 'sunlight'), they have determined the temperatures and densities of individual loops, and from this derived a scaling law for loop length with gas pressure. The various theories for the mechanism of coronal heating make different predictions for what this scaling law should be, so an unusual feat in this area of research - Klimchuk and Porter have supplied an observational means of discriminating between rival theories. To untangle the tale further will, they suggest, best be done by making direct measurements of the magnetic field strength in the loops.

Lindsay Nightingale 